\title{
The prevalence of depression in children and adolescents under 18 years of age treated for mental disorders in Poland between 2005 and 2016
}

\author{
Mira Lisiecka-Biełanowicz¹ ${ }^{1}$ Daria Biechowska², Edyta Orłowska³ ${ }^{3}$ Bartłomiej Molenda²
}

\begin{abstract}
'Department of the Prevention of Environmental Hazards and Allergology, Faculty of Health Sciences, Medical University of Warsaw, Warsaw, Poland 2Department of Public Health, Institute of Psychiatry and Neurology, Warsaw, Poland ${ }^{3}$ Institute of Psychology, University of Gdansk, Gdansk, Poland
\end{abstract}

Submitted: 7 March 2019; Accepted: 6 September 2019 Online publication: 18 April 2020

Arch Med Sci 2023; 19 (2): 371-380

DOI: https://doi.org/10.5114/aoms.2020.94530

Copyright $\odot 2020$ Termedia \& Banach

\begin{abstract}
Introduction: The prevalence of depression in Polish children and adolescents under 18 years of age treated for mental disorders has increased in the last few years in Poland. The purpose of this study was to examine the prevalence of major depression in a population of Polish children and adolescents under 18 years of age treated for mental disorders, stratified by sex and place of residence, in the years 2005, 2009, 2014, and 2016.

Material and methods: We analysed the psychiatric treatment data of children and adolescents under the age of 18 years in Poland compiled by the Institute of Psychiatry and Neurology in Warsaw for these years.

Results: Major depression was moderately prevalent among children and adolescents treated in all evaluated types of mental health facilities, with a prevalence in this population ranging from $0.8 \%$ in 2005 to $4.3 \%$ in 2016 . The rates of young patients with mood disorders increased from $3.1 \%$ in 2005 to $7.0 \%$ in 2016. Risk factors for developing major depression in our research group were: being female and living in an urban area.

Conclusions: Our findings suggest the need to increase the service capacity for children and adolescents as well as to intensify preventive measures to improve the mental health status of this age group.
\end{abstract}

Key words: depression, children and adolescents, psychiatric epidemiology.

\section{Introduction}

The World Health Organisation (WHO) predicts that, by the year 2020, major depression will be one of the most common mental disorders in the world [1]. Depression is a heterogeneous disease triggered by interaction between genetic, psychological, social, and lifestyle-related factors [2]. The incidence rates have been increasing systematically in adults, as well as in children and adolescents [3, 4]. As children and adolescents account for almost one-quarter of the global population, with $85 \%$ of them living in low- and middle-income countries, monitoring the prevalence of mental disorders in this age group is important $[5,6]$.

Empirical data show that mood disturbances during childhood are neither inevitable nor universal [7, 8]. Affective problems during these stages of physico-psychological development often involve major or mild

\author{
Corresponding author: \\ Bartłomiej Molenda \\ Department \\ of Public Health \\ Institute of Psychiatry \\ and Neurology \\ Sobieskiego St \\ 02-957 Warsaw, Poland \\ Phone: +48 602782157 \\ E-mail: bmolenda@ipin.edu.pl
}


depression, which affect $20 \%$ of the underage population globally $[9,10]$. The estimates differ depending on the country and diagnostic criteria. Studies are illustrating the growing rates of adolescent depression in developed countries, especially in individuals of young population between the ages of 13 and 18 years [11].

Research on the long-term physical health consequences of early-onset major depression has demonstrated that major depression is associated with considerable chronic physical health [12]. Over half of the individuals who recover from the first episode of depression will suffer at least one additional episode later in life, whereas approximately $80 \%$ of those with a history of two episodes will experience another recurrence [13].

As meta-analysis reports suggest, the proportion of the adult population experiencing any form of mood disorder represented by the available data in Eastern Europe is estimated at 0.47\%, which is extremely low when compared with the corresponding proportion of $17-40 \%$ in Western European countries. These data refer to general mood disorders, particularly anxiety [6, 14]. However, this disproportion may be influenced by differences in reporting rates between countries representing various economic status. The data for the Polish population are limited because no national comorbidity surveys, which are routinely performed in other countries, have been performed in Poland. The first ever Polish population-based study on the epidemiology of psychiatric disorders (EZOP 2012) aimed at assessing the prevalence of selected mental disorders in the adult population [14].

Therefore, the purpose of this study was to determine the prevalence of major depression in the population of children and adolescents, stratified by sex and place of residence, in the years 2005 , 2009, 2014, and 2016, in Poland, and to indicate an appropriate model of community-based treatment teams aimed at the specific needs of children and adolescents in Poland.

\section{Material and methods}

The assessment method adopted for this study included the analysis of data on the prevalence of depression among children and adolescents under 18 years of age treated for mental disorders in 2005-2016 in Poland, prepared by the Institute of Psychiatry and Neurology in Warsaw, Poland for the years 2005, 2009, 2014, and 2016. Our research was conducted mainly on the basis of the data collected from the following forms [15]: (1) MZ-15, the operation of outpatient healthcare facilities for people with mental disorders; (2) MZ19 , the activities of community mental-health teams; (3) MZ-30, the reported health care activity of $24 \mathrm{~h}$ health care providers; and (4) MZ/Szp-11B, individual patient stays in $24 \mathrm{~h}$ mental health care settings.

The data for the purpose of our study were gathered from mental health hospitals, day-care centres, $24 \mathrm{~h}$ mental health facilities, and community mental health teams. More specific data, including patient sex and place of residence, were gathered mostly from the first two types of facilities mentioned above. Most medical units were located in urban areas. In Poland there is no regionalisation in the health care system, and as such the data should not be impacted by rural residence of the treated population.

Below we present the size and dynamics of the selected mental health problems in a population of children and adolescents under 18 years of age treated for mental disorders in 2005-2016 in Poland, based on existing routine information systems. For many years, information about Polish residents treated for mental disorders in mental health care centres (hospitals, care and treatment centres) was collected as part of the National Psychiatric Hospital Disease Examination implemented by the Institute of Psychiatry and Neurology in Warsaw.

\section{Statistical analysis}

The results are published in the statistical yearbook issued by the Institute. The presented coefficients are related to people, not cases, because, for the purposes of statistical analysis, multiple hospitalisations were combined in accordance with the identification key determined by the Institute.

Microsoft Excel (Microsoft, Redmond, Washington, USA) was used to analyse the statistical data provided in yearbooks and compiled by psychiatric and neurological care institutions in the years 2005, 2009, 2014, and 2016. Our analysis included the general mental health status of Polish children and adolescents and the proportions of this patient population treated for any mental conditions in general, those treated for mood disorders, and those treated for major depression in particular. Mental disorders were classified by psychiatrists according to the $10^{\text {th }}$ revision of the International Classification of Diseases (ICD-10) [16] and reported on the basis of individual patient statistical cards.

\section{Results}

Over the analysed 12-year period, the number of children and adolescents under 18 years old who received treatment for any psychiatric conditions in mental-health hospitals and outpatient clinics for children and adolescents increased by 
20,111. Over the same 12-year period, the number of underage psychiatric patients treated in day-care centres increased by 870 , and the number of those treated by community mental-health teams increased by 1320 (993\%). We noticed, however, a decrease (by $30 \%$ ) in the number of patients treated in $24 \mathrm{~h}$ mental-health facilities. In 2009, a noticeable decrease occurred in the number of children and adolescents under 18 years old treated in mental-health outpatient clinics, daycare centres, and $24 \mathrm{~h}$ mental-health facilities. In comparison to the figures from 2005, the number of patients treated in all mental-health facilities increased by $17 \%$ by 2016 . Specific numbers of children and adolescents receiving psychiatric treatment in different types of mental health facilities in Poland are presented in Table I.

Major depression (diagnosed according to the ICD-10 criteria) was moderately prevalent in the population of patients treated in mental health facilities, with the proportion of affected patients ranging from $0.8 \%$ to $4.3 \%$ over the evaluated 12 year period. The specific figures for child and adolescent patients diagnosed with mood disorders in general and major depression in particular who were treated in mental hospitals and day-care centres are presented in Table II.

The data collected over the investigated time period indicated an increase in the prevalence of mood disorders among both day-care centres and mental hospital patients. The proportion of child and adolescent patients treated for mood disorders in day-care centres rose from $1.5 \%$ in 2005 , to $2.0 \%$ in 2009 , to $4.0 \%$ in 2014 , and to $5.0 \%$ in 2016 .

The rates of child and adolescent patients treated for mood disorders in mental hospitals were comparatively high, rising from $3.4 \%$ in 2005 , to $4.9 \%$ in 2009 , to $7.1 \%$ in 2014 , and eventually to $7.5 \%$ in 2016 . The rates in the combined population of child and adolescent patients treated in both of these types of health care facilities increased from $3.1 \%$ to $7.0 \%$ between 2005 and 2016 .

According to ICD-10, major depression is included in mood disorders (i.e. affective disorders); accordingly, these diagnoses were considered in our analysis. Our results showed a steady increase in the proportion of children and adolescents diagnosed specifically with depression out of all underage patients treated for mental problems. Between 2005 and 2016, this proportion increased from $0.8 \%$ to $3.4 \%$ among patients treated in daycare centres and from $2.0 \%$ to $4.3 \%$ among mental hospital patients. Of the combined population of children and adolescents treated in both these types of institutions, the rates of major depression were, respectively, $1.9 \%$ in $2005,2.4 \%$ in 2009 , $3.9 \%$ in 2014 , and $4.1 \%$ in 2016.

Data from 2005, 2009, 2014, and 2016 indicate that, among children and adolescents undergoing treatment in day-care centres and mental hospitals, a certain group of individuals were most susceptible to developing major depression symptoms. The proportions of children and adolescents diagnosed with mood disorders in general and major depression in particular (stratified by sex and place of residence) and treated in day-care centres and mental hospitals in Poland are presented in Tables III and IV. These tables present the rates of treatment for the evaluated mental conditions per 100,000 residents. Our data indicate that depressive disorders were most common among female children and adolescents who were urban residents, in all the years studied. This finding is significant because more male than female patients in general received treatment in mental health facilities over the evaluated 12-year period. In 2005, similar rates of young male and female patients (33.3\% and $66.7 \%$, respectively) were treated in day-care centres for both mood disorders in general and depression in particular. Of the patients

Table I. Total numbers of children and adolescents treated for major depression in various types of mental health facilities

\begin{tabular}{|lcccc|}
\hline Year & $\begin{array}{c}\text { Mental-health } \\
\text { hospitals and } \\
\text { out-patient clinics }\end{array}$ & Day-care centres & $\begin{array}{c}\text { Community } \\
\text { mental-health teams }\end{array}$ & $\begin{array}{c}\text { 24-hour } \\
\text { mental-health } \\
\text { facilities }\end{array}$ \\
\hline 2005 & 118,921 & 1771 & 133 & 9886 \\
\hline 2009 & 114,121 & 2155 & 119 & 9494 \\
\hline 2014 & 125,681 & 2545 & 1640 & 10,176 \\
\hline 2016 & 139,032 & 2641 & 1453 & 9856 \\
\hline $\begin{array}{l}\text { Difference } \\
\text { between 2005 } \\
\text { and 2016 }\end{array}$ & $+20,111$ & +870 & $+1,320$ & -30 \\
\hline
\end{tabular}

Source: Statistical reports from psychiatric and neurological health care facilities; the Polish statistical almanacs for the years 2005, 2009, 2014, and 2016 and the Institute of Psychiatry and Neurology, Warsaw. 


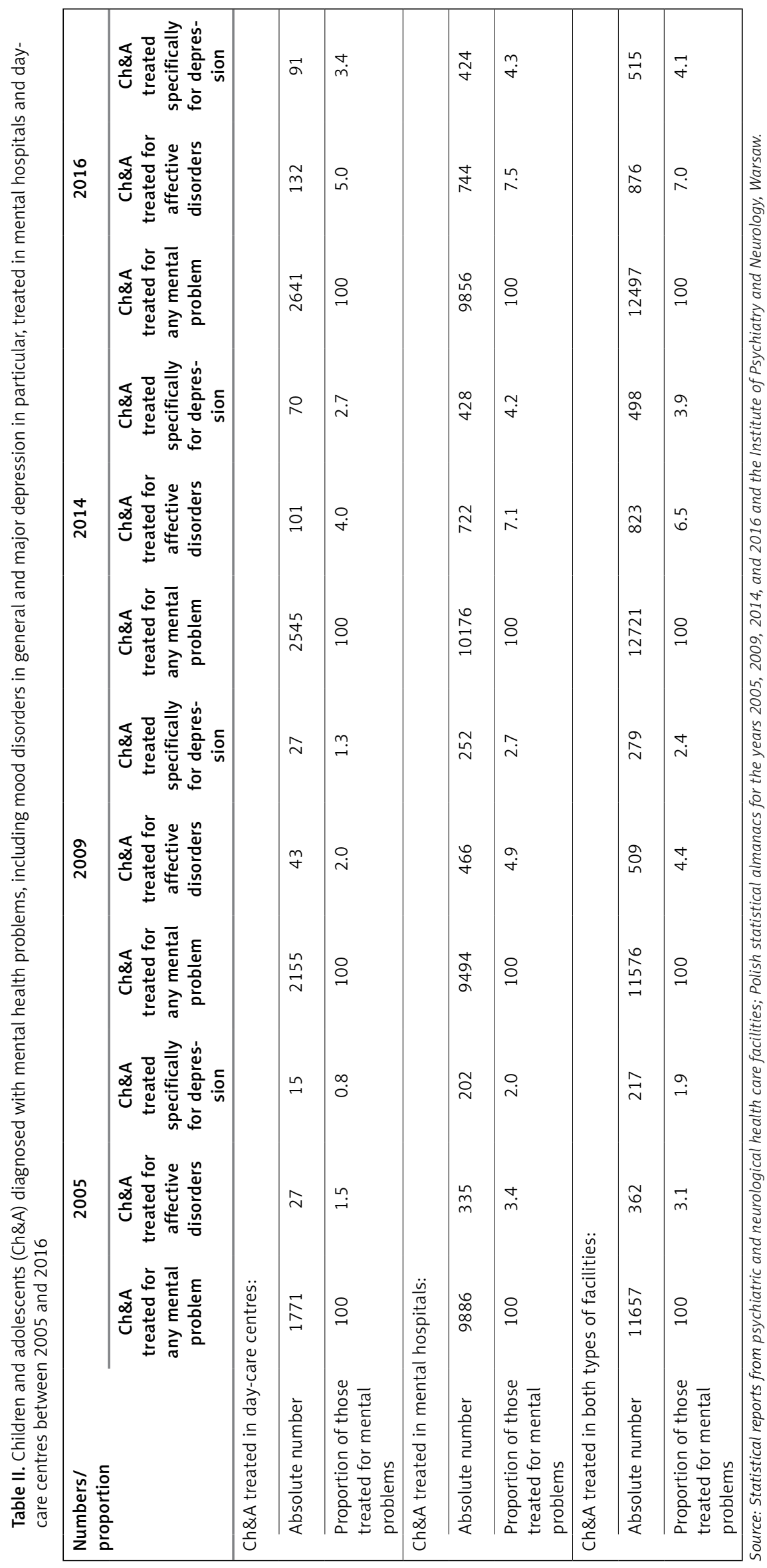




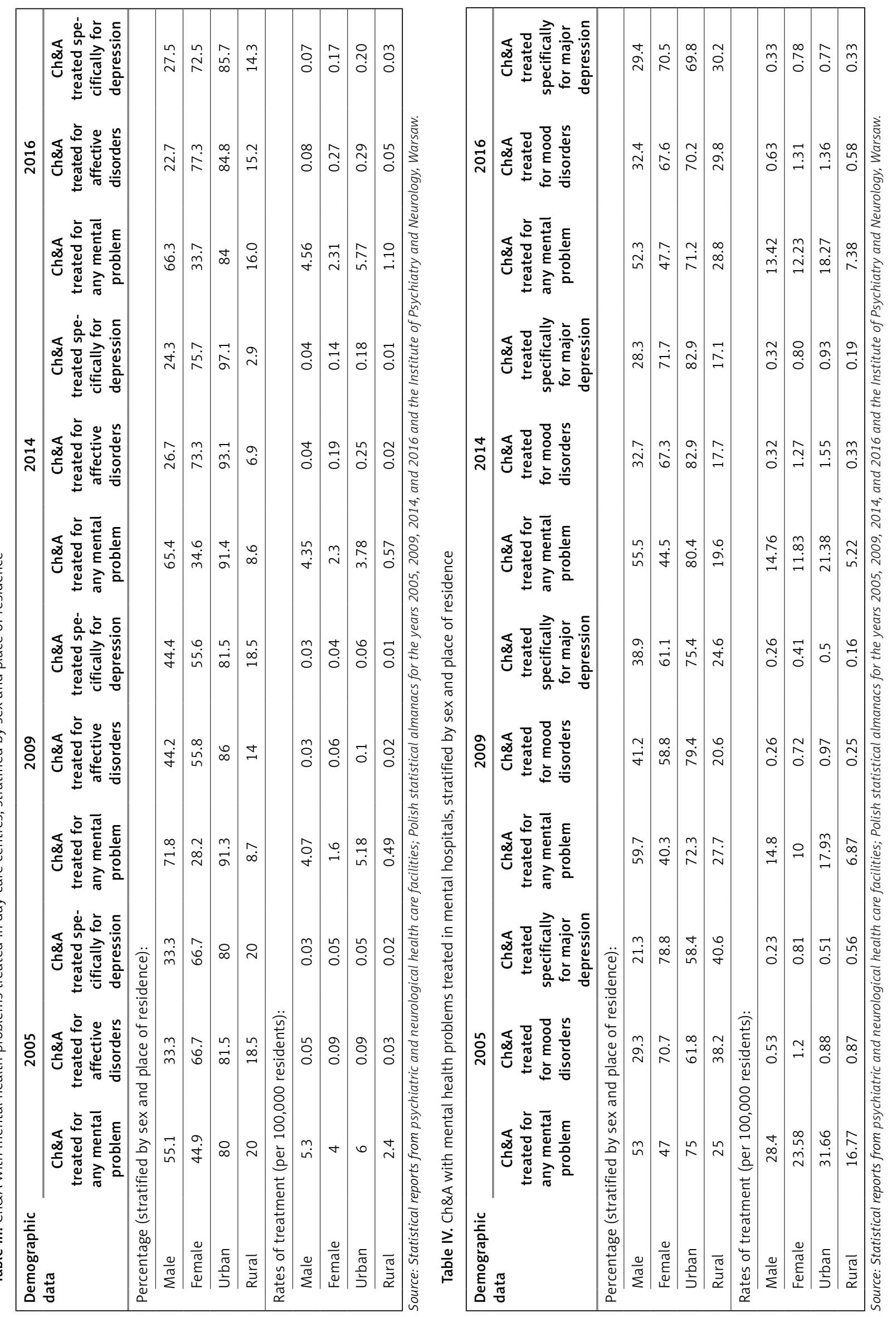


diagnosed with mood disorders and treated in mental hospitals in 2005, $70.7 \%$ were female and $29.3 \%$ were male, whereas out of all patients diagnosed with major depression, $78.8 \%$ were female and $21.3 \%$ were male. This indicates that female children were twice or even three times more likely to develop mood disorders (particularly major depression) in 2005. High female-to-male patient ratios among mental hospital patients were also observed in the subsequent years. Among daycare centre patients treated in 2009 , girls and boys constituted $55.8 \%$ and $44.2 \%$ of patients with mood disorders, respectively, and $55.6 \%$ and $44.4 \%$ of patients with major depression, respectively. Among mental-hospital patients treated in the same year, girls and boys constituted 58.8\% and $41.2 \%$ of mood-disorder patients, respectively, and $61.1 \%$ and $38.9 \%$ of depression patients, respectively. In 2014, $73.3 \%$ of day-care centre patients diagnosed with mood disorders were female and $26.7 \%$ were male; of those diagnosed with major depression, $75.7 \%$ were female and $24.3 \%$ were male. In the same year, these proportions were similar in mental hospitals, where $67.3 \%$ of mood-disorder patients were female and $32.7 \%$ were male, and where $71.7 \%$ of major depression patients were female and $28.3 \%$ were male. The situation in 2016 was analogical, as $77.3 \%$ of patients receiving treatment in day-care centres due to mood disorders were female and $22.7 \%$ were male, and $72.5 \%$ of patients treated for depression were female and $27.5 \%$ were male. Among young mental-hospital patients, girls and boys constituted $67.6 \%$ and $32.4 \%$ of patients treated for mood disorders, respectively, and $70.5 \%$ and $29.5 \%$ of patients treated for depression, respectively.

An analysis of the collected data in terms of the place of residence revealed that, of all patients in this age group treated for mood disorders in daycare centres in 2005, urban residents constituted $81.5 \%$ in $2005,86 \%$ in $2009,93.1 \%$ in 2014 , and $84.8 \%$ in 2016 . The corresponding proportions of urban residents among young patients treated for major depression were $80 \%$ in $2005,81.5 \%$ in $2009,97.1 \%$ in 2014 , and $85.7 \%$ in 2016.

The data for mental-hospital patients show that, of the patients in this age group treated for mood disorders, urban residents constituted $61.8 \%$ in $2005,79.4 \%$ in $2009,82.9 \%$ in 2014 , and $70.2 \%$ in 2016 . The corresponding proportions of urban residents among young patients treated for major depression were $58.4 \%$ in $2005,75.4 \%$ in $2009,82.9 \%$ in 2014 , and $69.8 \%$ in 2016 .

The rates of treatment per 100,000 population, stratified by sex and place of residence, were calculated based on the data published in Polish statistical yearbooks for the evaluated years and are presented in detail in Tables III and IV.

\section{Discussion}

Analysis of the data gathered for the evaluated years in the period from 2005 to 2016 demonstrated a $237 \%$ increase in the number of individuals under 18 years of age treated for major depression in our research group. The first ever Polish National Comorbidity Survey directed at the adult population showed the prevalence of depressive disorders among Polish adults to be very low, at 0.4\% (95\% confidence interval (Cl): 0.3-0.5) [17], with adults of all ages and both sexes being affected evenly. This figure differed from those presented in earlier reports from other countries, where the prevalence of depressive disorders was estimated to be between $9.8 \%$ in Israel and $21.0 \%$ in France $[18,19]$. The cited studies demonstrated higher prevalence rates in countries in which the survey response rate was higher than that in Poland. This discrepancy is not surprising because individuals refusing to participate in the study are often more severely affected by mental disorders than study participants [17]. Our analysis was based on the clinical data gathered by, and obtained from, daycare wards and psychiatric hospitals in the whole country. The research demonstrated a continually increasing number of children and adolescents treated for psychiatric disorders. This finding indicates an apparent worsening of the mental health status in this age group in Poland, because the actual prevalence of mental problems among children and adolescents in Poland is probably higher than what we observed. These findings raise concern because major depression is not a condition that can be completely cured. According to some studies, the risk of depressive episode recurrence in children and adolescents can be as high as 30$70 \%$ [20].

The increase in the rate of mental health issues recorded in Polish children and adolescents could be due to many factors within socio-economic changes after the dissolution of the Soviet Union. This was a great opportunity for rapid changes throughout the privatisation process in Poland but also introduced the risk of a negative impact on family life, especially for the young population. Rapid economic transformations could induce changes to the style of work, which also could affect the style of life and parents-children relations. Parents had less time to focus on their children and adolescents, which is one of the most important factors for their mental health.

The issue of the high prevalence rate of depression presented in our study cannot be explained with this basic data analysis, and more research is needed to explain this phenomenon. Evidently, because depression is a condition with complex aetiopathogenesis, many factors can contribute to this mental health problem being so common 
$[18,20]$. Literature provides a wide range of risk factors including biological, psychological, or social aspects of functioning [20]. Genetic susceptibility should not be responsible for disparity between the Polish population and young people living in other countries. Nevertheless, existing literature offers some evidence on risk factors connected with global changes in lifestyle of the younger population. Amongst them, spending more time on new media screen-based activities and less time on non-screen activities, obesity, the impact of social media, and peer-stress are strongly connected with increases in depression and suicide rates $[21,22]$. Those factors are not entirely new but were more often observed in Poland between 1995 and 2011 [23].

What is more, early signs of depression in young individuals can easily be unnoticed or misinterpreted (i.e. interpreted as youth rebellion or as temporary problems) by their parents. Consequently, these youngsters are not provided with an accurate diagnosis and timely therapy and have more time to develop more severe clinical conditions [24-26].

As for other risk factors of developing depression, stressful life events are often mentioned in the literature. They include experiences of loss, marital discord or family conflicts, changes in family financial situation, interpersonal conflicts, emotional disappointments or losses, chronic diseases, or death of a loved one, and, often mentioned, experiencing abuse [27, 28]. There remains a need to conduct more studies, to include all those factors and explain their possible contribution to the high prevalence of depression amongst the young population.

The data we gathered from mental health institutions indicate an increase in the number of treated cases of both mood disorders and major depression among children and adolescents. The proportion of child and adolescent patients with major depression increased from $1.9 \%$ of all underage mental health patients in 2005 to $4.1 \%$ in 2016. Similarly, the proportion of child and adolescent patients with mood disorders rose from 3.1\% of all underage mental patients in 2005 to $7.0 \%$ in 2016. This signifies the importance of intensifying the existing prevention programs, including those involving mental health screening among the general population of children and adolescents. Studies indicate that screening assessments among school youths lead to moderate (statistically significant) reductions in depression symptoms, and earlier intervention reduces the risk of depressive disorders in the future. Such preventive programs are especially effective in high-risk groups [29].

Mental health in Poland is deteriorating, which is indicated by the increased number of children treated for mental health problems. We should consider better access to mental health in Poland, which could occur in the period under consideration, as well as the general increase in social acceptance of psychiatric care. For these reasons, the increase in the pace of mental health problems in Polish children and adolescents is unclear.

Among all child and adolescent mental health patients undergoing treatment, the proportion of patients diagnosed with depression was higher in mental hospitals than in day-care centres. However, both types of mental health facilities experienced an increase in the proportion of underage patients with depression over the investigated 12year period. This was also true for general mood disorders. Our study shows that, despite the availability of other diagnostic and treatment facilities for mood disorders (including major depression), most Polish children and adolescents seek help in mental hospital wards. This finding raises the concern given in earlier quality-of-care reports, which indicate a better quality of care in units that are smaller and in which not all patients have severe mental problems [30]. However, very few mental health facilities in low- and middle-income countries, including Poland, offer services targeted at children and adolescents, and the level of personnel training on child and adolescent mental health issues is insufficient [31].

The results of our study are consistent with global trends because both the prevalence and the rates of treatment for major depression are increasing worldwide [9, 32-34]. Moreover, there is no doubt that, according to the EZOP research, every fourth adult Pole has mental health problems $[14,17]$. The use of specialty mental health providers is increasing, which leads to an increase in the use of prescribed medications and the rates of inpatient treatment [32, 33, 35-37].

Our analysis suggests that, in terms of sex, female children and adolescents are at a higher risk of developing depression, whereas, in terms of the place of residence, urban residents are at higher risk. Our results are consistent with those of other prevalence studies [17, 34, 38, 39] because women have been generally reported to be more likely than men to develop depression during their lifetime $[40,41]$.

Other findings also suggest that teenagers' intention to seek help for mental disorders significantly depends on social factors as well as the individual's sex (with girls being generally more likely to seek help than boys). The factor that inhibits help-seeking includes the gender norm regarding problem solving, with boys being more reluctant to seek help for depression than girls, and boys being expected to cope with problems on their own 
[42]. Relevant literature suggests that the female vulnerability to depression in the early years of life may be rooted in an intricate combination of genetic traits, normal female hormonal maturational processes, and gender socialisation [43].

The findings should be interpreted in the context of several limitations. Most notably, the study was not based on self-reports by children and adolescents but on clinical assessments reported by mental health institutions. Therefore, our survey (because we register treatment in the psychiatric care system) cannot be compared with traditional comorbidity surveys conducted in the general population of children and adolescents, because self-reports and parental reports are potentially more sensitive to capturing the initial symptoms of major depression $[44,45]$. On the other hand, self-reporting has its own limitations and is prone to over interpretation. Therefore, a clinical assessment can be considered as this study's advantage.

A second limitation is that our study addressed the population of patients already diagnosed with mood disorders and undergoing treatment. The current organisational solutions (regarding accessibility and the number of staff in health care facilities) within the Polish mental health care system better meet the needs of patients requiring comprehensive mental health care [46]. Changes in the way of thinking about mental health care for children and adolescents in Poland can also be seen to meet the objectives of the Polish National Mental Health Program, which stipulates the provision of child and adolescent mental health patients with any of the following: inpatient psychiatric care, outpatient mental health care, treatment at day wards, or care at home offered by a community-based team of health care professionals (Figure 1).

In conclusion, over the analysed period of 12 years, the number of children and adolescent patients undergoing anti-depression treatment increased for any psychiatric condition in mental-health outpatient clinics. Major depression

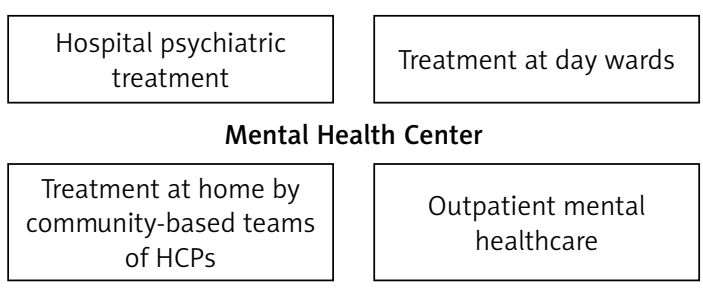

Figure 1 . The model of mental health care currently being implemented in accordance with the National Mental Health Program includes the Centre for Mental Health, which incorporates hospital psychiatric treatment, outpatient mental health care, treatment at day wards, and treatment by community-based teams of healthcare professionals (HPCs) [46] was moderately prevalent among children and adolescents treated in all evaluated types of mental health facilities, with its prevalence in this population ranging from $0.8 \%$ in 2005 to $4.3 \%$ in 2016. The rates of young patients with mood disorders increased from $3.1 \%$ in 2005 to $7.0 \%$ in 2016.

The increase in those treated for a mental disorder may be due to many reasons following the socio-economic changes which reshaped/redefined work and lifestyle, occurring over the last three decades in Poland. These kinds of changes could also be influenced by better access to psychiatric health care (with better quality of care in units that are smaller and in which not all patients have severe mental problems). Better access to health care could be improved by a socially higher - also in case of mental problems in children and adolescence - awareness about mental health through higher social acceptance of mental disorders. In the present study basic risk factors for developing major depression among young patients treated for mental disorders were being female and living in an urban area.

Our findings call for renewed efforts to expand the mental-health service capacity, intensify preventive measures, and better meet the mental health care needs of child and adolescent patients under the age of 18 years (especially for girls).

The National Mental Health Program is shifting the model of psychiatric treatment in Poland toward community-based care via Mental Health Centres in order to better meet the mental health care needs of children and adolescents, but we should continue to think about an appropriate model of community-based treatment teams aimed at the specific needs of this age group (children and adolescents) in Poland.

\section{Conflict of interest}

The authors declare no conflict of interest.

\section{References}

1. World Health Organization. Depression and Other Common Mental Disorders Global Health Estimates 2017.

2. Villas Boasad GR, Boerngen de Lacerdac R, Meirelles M, et al. Molecular aspects of depression: a review from neurobiology to treatment. Eur J Pharmacol 2019; 851: 99-121.

3. Bor W, Dean A, Najman J, Hayatbakhsh R. Are child and adolescent mental health problems increasing in the $21^{\text {st }}$ century? A systematic review. Austral N Z J Psych 2014; 48: 606-16.

4. Flisher AJ, Dawes A, Kafaar Z, et al. Child and adolescent mental health in South Africa. J Child Adolescent Mental Health 2012; 24: 149-61.

5. United Nations. World Population Prospects - The 2017 Revision. United Nations: New York 2017.

6. Erskine HE, Baxter AJ, Patton G, et al. The global coverage of prevalence data for mental disorders in children and adolescents. Epidemiol Psych Sci 2017; 26: 395-402. 
7. Ferdinand RF, Verhulst FC. Psychopathology in Dutch young adults: enduring or changeable? Soc Psychiatry Psychiatr Epidemiol 1995; 30: 60-4.

8. Patton GC, Coffey C, Romaniuk H, et al. The prognosis of common mental disorders in adolescents: a 14-year prospective cohort study. Lancet 1995; 383: 1404-11.

9. Kessler RC, Walters EE. Epidemiology of DSM-III-R major depression and minor depression among adolescents and young adults in the National Comorbidity Survey. Depress Anxiety 1998; 7: 3-14.

10. Cheung AH, Dewa CS. Canadian community health survey: major depressive disorder and suicidality in adolescents. Health Policy 2006; 2: 76-89.

11. Naicker K, Galambos NL, Zeng Y, et al. Social, demographic, and health outcomes in the 10 years following adolescent depression. J Adolesc Health 2013; 52: 533-8.

12. Thase ME. Managing medical comorbidities in patients with depression to improve prognosis. J Clin Psychiatry 2016; 77: 22-7.

13. Burcusa SL, lacono WG. Risk for recurrence in depression. Clin Psychology Rev 2007; 27: 959-85.

14. Kiejna A, Adamowski T, Piotrowski P, et al. Epidemiology of mental disorders and access to mental health care. EZOP - Poland" - research methodology. Psychiatr Pol 2015; 49: 5-13.

15. Journal of Laws of 1995 No. 88 item 439 Act of June 29 , 1995 on public statistics (the text available on: http:// isap.sejm.gov.pl/DetailsServlet?id=WDU19950880439), accessed on May 19, 2016.

16. World Health Organisation ICD-10 Classification of Mental and Behavioural Disorders: Clinical Descriptions and Diagnostic Guidelines. World Health Organisation, Geneva 1992.

17. Kiejna A, Piotrowski P, Adamowski T, et al. The prevalence of common mental disorders in the population of adult Poles by sex and age structure - an EZOP Poland study. Psychiatr Pol 2015; 49: 15-27.

18. Alonso J, Angermeyer MC, Bernert S, et al. ESEMeD/ MHEDEA 2000 Investigators, European Study of the Epidemiology of Mental Disorders (ESEMeD) Project. Prevalence of mental disorders in Europe: results from the European Study of the Epidemiology of Mental Disorders (ESEMeD) project. Acta Psychiatr Scand Suppl 2004; 420: 21-7.

19. Bromet EJ, Gluzman SF, Paniotto V, et al. Epidemiology of psychiatric and alcohol disorders in Ukraine: findings from the Ukraine World Mental Health survey. Soc Psychiatry Psychiatr Epidemiol 2005; 40: 681-90.

20. Birmaher B, Arbelaez C, Brent D. Course and outcome of child and adolescent major depressive disorder. Child Adolesc Psychiatr Clin N Am 2002; 11: 619-37.

21. Mojs E, Warchoł-Biedermann K, Głowacka M, Strzelecki W, Ziemska B, Samborski W. Are students prone to depression and suicidal thoughts? Arch Med Sci 2013; 11: 605-11.

22. Twenge JM, Joiner TE, Rogers ML, Martin GN. Increases in depressive symptoms, suicide-related outcomes, and suicide rates among U.S. adolescents after 2010 and links to increased new media screen time. Clin Psychol Sci 2018; 6: 3-17.

23. Dudek M, Kasznia-Kocot J, Giel K. Trends of selected health behaviors of Polish youth aged 13-15 the European and worldwide studies between 1995-2011. Environm Med 2015; 18: 74-80.

24. Fergusson DM, Woodward LJ. Mental health, education$\mathrm{al}$, and social role outcomes of adolescents with depression. Arch Gen Psychiatry 2002; 59: 225-31.
25. Indic P, Murray G, Maggini C, et al. Multi-scale motility amplitude associated with suicidal thoughts in major depression. PLoS One 2012; 7: e38761.

26. Gladstone T, Beardslee WR, O'Connor E. The prevention of adolescent depression. Psychiatr Clin North Am 2011; 34: 35-52.

27. Shannon KE, Beauchaine TP, Brenner SL, Neuhaus E, Gatzke-Kopp L. Familial and temperamental predictors of resilience in children at risk for conduct disorder and depression. Dev Psychopathol 2007; 19: 701-27.

28. Mojs E, Bartkowska W, Kaczmarek ŁD, Ziarko M, Bujacz A, Warchoł-Biedermann K. Psychometric properties of the Polish version of the brief version of Kutcher Adolescent Depression Scale - assessment of depression among students. Psychiatr Pol 2015; 49: 135-44.

29. Stice E, Shaw H, Bohon C, Marti CN, Rohde P. A meta-analytic review of depression prevention programs for children and adolescents: factors that predict magnitude of intervention effects. J Consult Clin Psychol 2009; 77: 486-503.

30. Killaspy H, Cardoso G, White S, et al. Quality of care and its determinants in longer term mental health facilities across Europe: a cross-sectional analysis. BMC Psychiatry 2016; 16: 31.

31. Morris J, Belfer M, Daniels A, et al. Treated prevalence of and mental health services received by children and adolescents in 42 low-and-middle-income countries. J Child Psychol Psychiatry 2011; 52: 1239-46.

32. von Soest T, Wichstrøm L. Secular trends in depressive symptoms among Norwegian adolescents from 1992 to 2010. J Abnormal Child Psychol 2014; 42: 403-15.

33. Mojtabai R, Olfson M. National trends in the prevalence and treatment of depression in adolescents and young adults. Pediatrics 2016; 138: e20161878.

34. Twenge JM, Joiner TE, Rogers ML, Martin GN. Increases in depressive symptoms, suicide-related outcomes, and suicide rates among U.S. adolescents after 2010 and links to increased new media screen time. Clin Psychol Sci 2017; 6: 3-17.

35. Sigfusdottir ID, Asgeirsdottir BB, Sigurdsson JF, Gudjonsson $\mathrm{GH}$. Trends in depressive symptoms, anxiety symptoms and visits to healthcare specialists: a national study among Icelandic adolescents. Scand J Public Health 2008; 36: 361-8.

36. Sweeting $H$, Young R, West P. GHQ increases among Scottish 15 year olds 1987-2006. Soc Psychiatry Psychiatr Epidemiol 2009; 44: 579-86.

37. Fleming TM, Clark T, Denny S, et al. Stability and change in the mental health of New Zealand secondary school students 2007-2012: results from the national adolescent health surveys. Austral N Z J Psychiatry 2014; 48: 472-80.

38. Avenevoli S, Swendsen J, He JP, et al. Major depression in the national comorbidity survey- adolescent supplement: prevalence, correlates, and treatment. J Am Acad Child Adolescent Psychiatry 2014; 54: 37-44.e2.

39. Skovlund CW, Kessing LV, Mørch LS, Lidegaard $\varnothing$. Increase in depression diagnoses and prescribed antidepressants among young girls. A national cohort study 2000-2013. Nordic J Psychiatry 2017; 71: 378-85.

40. Kuehner C. Why is depression more common among women than among men? Lancet Psychiatry 2017; 4: 146-58.

41. Polikandrioti M, Tzirogiannis K, Zyga S, et al. Effect of anxiety and depression on the fatigue of patients with a permanent pacemaker. Arch Med Sci Atheroscler Dis 2018; 3: 8-17. 
42. Ando S, Nishida A, Usami S. et al. Help-seeking intention for depression in early adolescents: associated factors and sex differences. J Affective Disord 2018; 238: 359-65.

43. Born L, Shea A, Steiner M. The roots of depression in adolescent girls: is menarche the key? Curr Psychiatry Rep 2002; 4: 449-60.

44. Sourander A, Helstelä L, Helenius H. Parent-adolescent agreement on emotional and behavioral problems. Soc Psychiatry Psychiatr Epidemiol 1999; 34: 657-63.

45. Martin JL, Ford CB, Dyer-Friedman J, Tang J, Huffman LC. Patterns of agreement between parent and child ratings of emotional and behavioral problems in an outpatient clinical setting: when children endorse more problems. J Developm Behav Pediatr 2004; 25: 150-5.

46. Lisiecka-Biełanowicz M, Biechowska D, Cianciara D. Funkcjonowanie jednostek $w$ różnych formach opieki psychiatrycznej w Polsce w latach 2010-2013. Analiza organizacyjna i ekonomiczno-finansowa. Psychiatr Pol 2018; 52: 143-56. 